\title{
How accounting begins: object formation and the accretion of infrastructure
}

\author{
Abstract \\ Drawing on the case of accounting for the impact of research in UK universities, and building \\ on key contributions to Accounting, Organizations and Society, the paper explores the \\ conditions under which new accounting systems begin and the unfolding dynamics by which \\ vague performance objects becoming operational. Accounting for research impact involves a \\ radical change in the landscape of UK universities. At the centre of this change process is the \\ progressive construction of the Impact Case Study (ICS) as a new unit of performance \\ accountability for UK universities. Inductively, the emergence of the ICS suggests a fourfold \\ developmental schema for accounting origination spanning field and organization level \\ changes: policy object formation, object elaboration, activity orchestration and practice \\ stabilization in infrastructure. Drawing upon existing scholarship, the paper uses the impact \\ accounting setting to explore the dynamics of this developmental schema and its implications \\ for calculation, subjectivization and the structuring of organizational temporalities. The case \\ of impact in UK universities shows that accounting never simply begins but has multiple \\ conditions of possibility which align as drivers for change at both field and organization \\ level. The case of impact accounting also reveals the significance of managerial \\ infrastructures during accounting origination and this is suggestive of a future research \\ agenda.
}

KEYWORDS: IMPACT; ACCOUNTING; INFRASTRUCTURE; RESEARCH; UNIVERSITIES; EVALUATION 
"It is rarely possible to witness the birth pains of a newly emergent accounting" (Hopwood, 1987: 214),

On the $28^{\text {th }}$ of November 2011 a UK university, hereafter UNI, held a workshop, for nearly 100 academic staff to discuss the process of producing case studies to demonstrate the 'impact' of their research. The attendees had all previously produced drafts and the workshop, the first of several, was intended to assist in their further development and refinement. The need to produce such impact case studies (ICSs), a consequence of an impending research evaluation exercise for all universities in the UK, was taken as largely accepted. Debate about the merits of the policy and its accounting requirement was over. The organizational discussion from this point onwards would be operational in nature, focusing on the meaning of the regulatory requirement to demonstrate impact, the guidance for which was itself evolving at this time, and on the task of successfully crafting a sufficient number of 'high quality' research ICSs for independent evaluation. This group of UNI academics at the meeting represented nearly one fifth of the total academic staff. They had self-selected to attend the meeting, being those who considered themselves to be 'impactful' in some broad sense of that term. As clever as they all were, they did not realise that they were collectively engaged in the work - 'institutional work' (Lawrence et al., 2011) - of creating of an entirely new performance accounting instrument and its associated practice infrastructure.

The case of the Research Excellence Framework (REF) in the United Kingdom, and its requirement for universities to demonstrate the (beneficial) impact of their research activities, is of broader interest because opportunities to study the creation of 'new' accounting systems are rare. For example, Hopwood analysed the emergence of Joshiah Wedgwood's cost 
accounting practice and the rise and fall of value added accounting (Burchell et al, 1985; Hopwood, 1987 respectively). In addition, Preston et al. (1992) addressed the rise of new budgeting systems in the UK National Health Service. Yet, as we shall see, 'newness', 'innovation' 'creation', 'beginning' and related concepts cannot be taken for granted. If accounting has no 'essence' (Hopwood, 1987), it is likely to have multiple conditions and sources of beginning.

The emergence and refinement of the ICS as an 'accounting instrument' within universities was rapid and became a widely operationalised accounting form in the UK sector by the time of the REF submission date in late 2013. At the time of writing it is not clear whether the ICS as a specific form of accounting will have stability over the long term, but there is no doubting that UK universities have invested, and will continue to invest, in an impact and engagement infrastructure in the form of new roles, oversight structures and data collection processes. In other words, the performance discourse of impact has been firmly established and accepted in a set of activities and routines and new academic habits have started to be visible as individuals pay more attention to aspects of their work which have previously been taken for granted. Many actively collect traces of their impact outside the academy and are encouraged to construct narrative accounts out of these traces which can be made public. This emerging mode of self-governance in the name of impact is unevenly distributed across academic disciplines and individuals - it is not yet a field of practice in its own right - yet it represents a radicalisation of prior managerial trends in higher education by institutionalising the demonstrable use value of research as a new norm of academic performance evaluation for universities, their managements and academic staff.

This essay addresses the emergence and operationalisation of impact accounting in the period 2008-2014 with two principle motivations. The first specific motivation is that the case of 
impact accounting is interesting in its own right, not least as an intensification of a latent productionist logic of academic labour. The case description draws on several sources: deep participant observation as a member of UNI's strategy committee for research 2013-14 (approximately 12 meetings in total); a reading of policy documents at the regulatory level; and observation of, and participation in (as an ICS author), of their operationalisation at the organization level. The methodological disadvantages of opportunistic case selection and associated biases are partially offset by the second motivation of the paper which is to consolidate and extend existing theory (Eisenhardt, 1989) and to explore the question of 'how accounting begins' by revisiting some of the major theoretical reference points in Accounting Organizations and Society. ${ }^{1}$ Taking these two motivations together, the analysis is theorybuilding in spirit by iterating between the details of this specific case and some key, and potentially generalizable, features of the emergence of new accounting systems.

The argument begins with the wider institutional context of the case, namely the emergence of the UK requirement for universities to demonstrate research impact. This is briefly described and situated within a long history of efforts to enrol research as an engine of economic growth. Importantly, in this setting there is no 'critical event' in the sense of a scandal or disaster which forces actors to rethink existing practice. Rather, there is a longstanding cultural tension between two underlying logics of university research work - on the one hand the logic of academic autonomy and a curiosity driven agenda for research and, on the other hand, a productivist valuation of research for its use-value. ${ }^{2}$ Yet in the UK

\footnotetext{
${ }^{1}$ The focus of this essay is mainly upon the contribution of accounting scholarship within the journal Accounting, Organizations and Society. It is therefore deliberately partial and does not deal with scholarship about accounting origination and change in other journals, such as Critical Perspectives on Accounting and the Accounting, Auditing \& Accountability Journal.

${ }^{2}$ See Habermas (1987) for a version of this tension in terms of functionalist and communicative roles of the university.
} 
something changes in higher education policy with the advent of idea of 'impact' in the mid2000s and this marks a decisive shift in the balance of power between these two logics. In addition, this shift is also enabled by the increasing world-level and cross-sectoral significance of the idea of impact for government and non-profit organizations of many different kinds in increasingly austere public funding environments. 'Impact' in the higher education field has the character of a boundary object (Star, 2010) which is essentially flexible in its interpretation but must also be made specific by the work of higher education regulators and universities, specifically via the iterative development of a standardized template for the form of the ICS. While the initial policy dream was for the measurement of impact, university regulators, in negotiation with lead universities, gravitated towards a case study form i.e. a narrative approach to impact supportable by, but not wholly defined in terms of, metrics.

The second section deals with the production of ICSs at the organizational level, based on the case of UNI and the author's participant observation of the process. In the early phases of development, the process is best conceptualised as a collection of activities by different actors which are not yet a practice (Lounsbury and Crumley, 2007). At this local level 'groups cooperating without consensus go back and forth between both forms of object.....vague and specific' (Star, 2010: 605). Initially there is much local misunderstanding at UNI about impact. The production of a stable ICS form and its content becomes an issue of how to 'collect, discipline, coordinate distributed knowledge' (Star, 2010:607). For this reason, central control of the production of the ICSs at UNI increases over time and generates processes for the construction of a durable infrastructure for managing knowledge exchange and impact. Only at the point of 'infrastructure embedding', does impact acquire the status of what might be called a 'practice logic' for academic research. Via the iterated development 
of the ICS as an accounting instrument, the vague logic of impact as an organizing principle is realized in a material and form.

In the third section, the genesis of the ICS is used to explore more general issues about 'accounting beginnings'. The argument combines insights from existing accounting scholarship with those of innovation studies (e.g. Lounsbury and Crumley, 2007; Nigam and Ocasio, 2010; Padgett and Powell, 2012). Specifically, this section argues, partly inductively from the case and partly deductively by consolidating existing work, for a simple model (See Figure 1) of new accounting development which visualizes four sequential and cumulative phases: object formation; object elaboration; activity orchestration; and practice stabilization via infrastructure. Within the event window of the case analysis, earlier phases and their respective objects and workstreams are not simply superseded but continue to influence and be influenced by successive phases, thereby contributing to the accretion of elements of a transorganizational sociotechnical infrastructure. Impact operates as a boundary object in Star's (2010) sense in so far as people act towards it via material work processes which, as they scale up, become embodied in standards and in infrastructure.

From this point of view, the emergent form of the ICS instrumentalizes, makes operational and 'translates' (Robson, 1991) an ambiguous policy object, namely research impact, into structures and routines capable of reproducing themselves. In short, practice norms of accounting for impact are born from a dynamic of repeated iterations between institutional requirements and local activities (Halliday and Carruthers, 2007) with each specific version of an ICS being a kind of experiment and a test for all the others.

This is, admittedly, not a very surprising or particularly original model of the dynamics of accounting initiation and institutionalization. But it suggests a line of theoretical sight in two potentially fruitful directions. The first is the possibility of positioning some of the constructs 
which interest accounting researchers, such as 'problematisation', 'mediation' and 'centres of calculation', in a dynamic relation to one another. The second is to emphasise the significance of infrastructure as the often invisible and neglected ground of visible accounting practices. Of course, such a concept of organizational infrastructure is itself a problematic rather than a self-evident category. It sits uneasily between field level, institutionalist and practice-specific, materialist conceptualizations of it. ${ }^{3}$ However, the paper argues that this problematic notion of infrastructure is worth exploring further in order to understand the possible future dynamics of impact accounting in three thematic areas which remain central to the preoccupations of accounting scholars, namely: the continuing policy aspiration for the measurement of impact; the creation of a new kind of 'governed' academic subject; and changes in organizational temporalities. Three propositions are advanced for further consideration and empirical exploration.

\section{The impactization of UK universities}

The history of science policy is a long one involving periodic efforts by UK government to harness publicly funded science in universities more explicitly for social and economic ends (Robson, 1994). Indeed, in many countries the economic value of science has been widely debated, reflecting both pressures to demonstrate its 'value for money' and strategic significance for national competitiveness (Dasgupta and David, 1994; Narin et al,. 1997; Mansfield, 1990; Pavitt, 1990), and also recognition of the historical trajectory of innovation and entrepreneurship in universities (Etzkowitz, 2003) A recent manifestation of this continuous policy effort to link science to economy at the university level is the UK

\footnotetext{
${ }^{3}$ For example, Star (2010:611) characterises infrastructure as: "embedded.... transparent to use but itself invisible (until its breaks down)....has reach in time and space...is learned as part of group membership... is linked with conventions of practice....embodies standards... is built on an installed base....is fitted in modular increments rather than all at once".
} 
requirement for research councils and other higher education funding bodies to prove, and account for, the economic and social impact of the academic research which they, and ultimately taxpayers, fund. The publication of the Warry Report in 2006 was a catalyst for this change: its recommendations were directed at the various research councils in the UK, but it was itself a reflection and crystallisation of extensive prior debates about effective knowledge transfer between universities and the need to enrol 'users' of research. The report recommended that: 'Research Councils should make strenuous efforts to demonstrate more clearly the impact they already achieve from their investments... It is important to measure outcomes, however difficult, rather than outputs (Warry Report, 2006: 5 - emphasis added). A number of the UK research councils - bodies to whom academics apply for research funding - had already been exploring ways of evaluating their impact and gave evidence to the Warry committee. For example, the Economic and Social Research Council (ESRC which funds social science research) had already identified the critical issues for impact assessment, such as difficulties of quantification, attribution, time-lags, and environmental factors. These analyses informed their subsequent efforts to develop more pluralistic and experimental approaches to research impact based on case studies (ESRC, 2009). The UK research councils acted collectively as an umbrella organization - RCUK - and commissioned studies from consultants in the impact evaluation space, including a user satisfaction survey by PwC in $2007 .^{4}$

The Warry Report gave new momentum to an already existing knowledge exchange and research impact agenda in UK higher education and research ${ }^{5}$, but its conditions of possibility lie in the broader and more globally distributed history of policy evaluation more generally,

\footnotetext{
${ }^{4}$ http://www.rcuk.ac.uk/RCUK-prod/assets/documents/keireports/ussurvey.pdf

${ }^{5}$ For example, in the UK the ESRC developed a Knowledge Transfer and Impact Strategy in 2007.
} 
such as in welfare and development programmes. For example, the concept of impact analysis has been at the heart of the World Bank's reform agenda for many years (Ezemanari et al., 1999; Khandker et al., 2010), and underpins practices of environmental impact assessment, social impact analysis and many more. In these and other settings the idea of 'impact' has acquired normative force and legitimacy as a policy value, not least by implying the possibility of precise measurement despite the widespread acceptance on the ground that impact is likely to be complex and non-linear. 'Impact' is an attractive policy concept because it connotes, at least in ambition if not realisation, something visible, clear, objective and calculable in which relevant activity, such as research, can be causally linked to a desired policy outcome. From this point of view, the demand to demonstrate impact in the Warry Report mediates between this wider impactization of global policy thinking, with its focus on demonstrable outcomes, and the specific field of UK public science. ${ }^{6}$ This in turn reflects the rise of ideals of evidence-based decision making, not least in education policy. ${ }^{7}$

In addition to dedicated research councils, the regulation and funding of research in the United kingdom is the responsibility of four bodies as a result of devolution (hereafter the 'UK Funding Councils'), namely the Higher Education Funding Council for England (HEFCE), the Scottish Funding Council (SFC), the Higher Education Funding Council for Wales and the Department for Employment and Learning in Northern Ireland. The four bodies receive their funding from the UK Treasury and award it to universities. In the case of academic research, funding is awarded on the basis of a periodic competitive research

\footnotetext{
${ }^{6}$ A full pre-history of the Warry report and its aftermath is beyond the scope of the present paper.

${ }^{7}$ Impact was also independently debated by business schools around the world (e.g. AACSB, 2008) in the wake of concerns about declining relevance and being 'too academic'.
} 
evaluation exercise, the most recent of which is the Research Excellence Framework (REF). ${ }^{8}$ The results of the most recent REF were announced in December 2014, and it has always been branded as "REF2014". 9 An 'impact window' was determined by the funding councils which ran from January $1^{\text {st }} 2008$ until July $31^{\text {st }} 2013$ and could be based on work since 1993 . $20 \%$ of total funding for universities was to be awarded on the basis of an assessment of their research impact, a lower percentage than originally proposed but enough to make the impact assessment scheme economically consequential for UK universities.

\section{Elaboration and negotiation}

Originally framed narrowly in terms of economic benefit to the UK alone, impact came to be defined to include 'all kinds of social, economic and cultural benefits and impacts beyond academia' (Funding Councils, 2011, para 11.a). The approach also shifted from the strong emphasis on measurement in the Warry Report towards a case study based approach which might embody diverse methods of assessing impact. ${ }^{10}$ Indeed, the post-Warry project of RCUK to develop algorithms to measure the economic impact of research had more or less failed (Corbyn, 2008), thereby necessitating the next best practical option in the form of a case-based approach, which was taken up by HEFCE on behalf of all the funding councils. HEFCE enrolled universities in a number of pilot exercises in 2009 in order to refine its own

\footnotetext{
${ }^{8}$ Similar research evaluations have taken place in other countries e.g. Netherlands (Geuna and Martin, 2003) and Australia (Garrett-Jones, 2000), copying and adapting the UK approach even as it was heavily criticised at home.

${ }^{9}$ For the full results go to $\underline{\text { www.ref.ac.uk }}$

${ }^{10}$ This is not to ignore a strong and continuing interest in bibliometric methods to measure the quality of research, at least in the natural sciences (Weingart, 2005; van Raan, 2005).
} 
regulatory and advisory role with the help of models and benchmarks of the way in which impact could be demonstrated as part of the REF2014. ${ }^{11}$

As the HEFCE guidance to English universities developed over 2011-12, efforts were made to define and refine impact. Importantly, guidance was produced to clarify what impact is not. For REF2014 it was made clear that impact is not outreach, knowledge transfer or impact within the academic sphere itself in terms of advancing knowledge or teaching. Impact was not to be understood as the public engagement of academics in policy debates, although such activities could be a 'pathway to impact' and a way of linking specific research to demonstrable benefits. In other words, public lectures, advice to public policy committees, and other external engagement activities could result in impact but were not themselves to be regarded as examples of impact. ${ }^{12}$ The intention was therefore to define impact very specifically in terms of a verifiable causal pathway, despite the acknowledged problem of attribution, between identifiable pieces of research and beneficial outcomes broadly defined. For example, in later documents the Funding Councils emphasise a range of ways of thinking about impact, giving many examples but repeatedly pointing out that such examples are not exhaustive (Funding Councils 2012). In the context of the social sciences (relevant to UNI) these examples include 'holding public bodies to account' and 'contribution to critical public debate. ${ }^{13}$ While this range of ideas about impact was essentially pluralistic, in contrast to the economic emphasis in the Warry report which set the process in motion, importantly the quality threshold was lowered for impactful research. Whereas the gold standard for the

\footnotetext{
${ }^{11}$ See http://www.hefce.ac.uk/research/ref/impact/

${ }^{12}$ The Warry report provides a visual representation of this knowledge transfer process that might result in impact but should not be confused with it.

${ }^{13}$ This is as close as the formal guidance comes to supporting a more frictional conception of impact
} 
highest quality research was something calibrated as "Four Star", the hurdle for impactful research was set at "Two Star" - significantly lower. ${ }^{14}$

While the understanding of impact becomes more diverse, there remained a strong emphasis on verification and evidence: 'In assessing impact case studies, sub-panels will consider both the chain of evidence linking excellent research within the submitting unit to the impact(s) claimed, and the evidence of the reach and significance of the impact.' (Funding Councils, 2012, p.71) However, it was accepted that evidence may come in a variety of forms and there was no wish to pre-judge forms of evidence (Funding Councils, 2012, p.71). Again, the documents give examples of a wide range of possible forms of evidence, including citation beyond academic journals in public documents.

It is no surprise that the impact initiative, which was intended to supplement peer review evaluation practices, was initially highly controversial, particularly for arts and humanities disciplines and also for social sciences (Collini 2009). Many saw it as yet more evidence of creeping managerialism in the UK university sector (e.g. Head , 2011). Despite policy gestures towards the non-linearity and complexity of impacts, the very notion was regarded as inappropriate for many, but importantly not all, academic disciplines. So resistance to impact was very unevenly distributed in the academic field, with some disciplines, such as medicine, engineering and social policy, seeming to perceive more opportunity than threat. In addition, UK university management teams simply had to focus on the job of compliance

\footnotetext{
${ }^{14}$ Four star is defined as "Quality that is world-leading in terms of originality, significance and rigour". Two star is defined as "Quality that is recognised internationally in terms of originality, significance and rigour". See http://www.ref.ac.uk/panels/assessmentcriteriaandleveldefinitions/. The differences in these two standards of quality ( as well as Three star and one star) may appear very subtle to the uninitiated and assessments panels were faced with the task of making very fine judgements. However, Four Star could generally be interpreted as code for publication in the 'leading' global i.e., North American, journals as legitimated by established journal lists.
} 
with the accounting requirement - in the form of production of the case studies - which would support the evaluation exercise. Critique continued but it gave way to workstreams and efforts to operationalize. Indeed, the economic motives for compliance were obvious: the value of an impact case study would be significant with a high quality ("four star") impact study being 'worth' nearly four high quality academic papers in money terms, approximately $£ 120,000$. For these reasons, and the important fact that not all research or researchers would need to be impactful, the requirement was quickly normalised.

In summary, and in a short period of time, UK universities and their regulators - the funding councils - had fully embraced and sought to operationalise the impact agenda guided by pilot studies and emerging norms of best practice. Conferences on impact were held, impact videos and podcasts were created, and funding councils began to award prizes to celebrate impact. ${ }^{15}$ In short, some elements of an impact apparatus or infrastructure started to be created. And at the very heart of this explosion of impact in higher education was the progressive formation of the impact case study - the ICS - as a new unit of individual and organisational performance accounting.

\section{Producing the impact 'case study'}

The early pilot studies were both a mechanism for clarifying and negotiating the approach to accounting for impact and also a way of generating 'bottom up' regulatory knowledge for HEFCE and other funding councils (Technopolis Ltd, 2010). UNI participated in these studies and a small number of academics were influential in shaping early ideas about how to

\footnotetext{
${ }^{15}$ E.g. http://www.ox.ac.uk/research/research impact ;'Celebrating impact' Society Now Summer 2013, pp1414; Science Summitt: Making an Impact. Woburn House, London, December $3^{\text {rd }} 2014$. http://www.esrc.ac.uk/research/evaluation-impact/index.aspx
} 
report on impact in the social sciences. From these exchanges between HEFCE and universities there emerged during 2011 a benchmark of one ICS per ten members of staff per academic 'unit of assessment' (broadly understood as an academic discipline). The rationalization of this ratio was that if it was higher, then the institution would be shifting its strategy towards 'consultancy', but if it were lower then conversations with funding bodies and 'grumpy Treasury officials' would be difficult. One in ten became a norm, yielding an initial target in 2011 of approximately 65 case studies for UNI. ${ }^{16}$

Proposals and drafts for approximately 100 draft case studies were initially received by the central research office. At the workshop in November 2011 organized for the case study producing academics, it was acknowledged that all of them would need additional work and some might drop out of consideration ${ }^{17}$. The workshop was an opportunity to share common issues. It was clear that senior management at UNI perceived themselves to be in competition with universities with more developed knowledge transfer mechanisms, such as science parks. Many of the cases submitted were individual in nature rather than, as might be the case with the natural sciences, collective and corporate. Concerns were expressed about how joint work, especially across institutions, could be properly 'accounted' for since the very idea of impact seemed to presuppose a single institutional source. Indeed, the institutional ownership of ICSs became more of an issue as time progressed. However, most discussion and deliberation at the workshop focused on the design and content of the impact statement itself as an accounting instrument, not least in consolidating the standardised structure and size for the reporting of research impact proposed by HEFCE and revealed in the pilot

\footnotetext{
${ }^{16}$ For all UK universities, 52061 staff were submitted to REF2014 and they produced 6975 ICSs - a ratio of 1:7.5. This is a higher actual ratio than the 1:10 target, explainable in part by the fact that universities did not submit all their research staff to the REF. See www.ref.ac.uk

${ }^{17}$ Those ICSs which were not developed or used remain in play as possible 'assets' for REF2020.
} 
studies. The individual ICS would be 3-4 pages long and should adopt a structure based on the Funding Councils' initial ICS template' providing indicative maximum word lengths for each of the sections (See Appendix 1 which is an edited extract of the HEFCE template).

Although each ICS would be different and unique, the template would make them visually similar and of a manageable length for the evaluation process. In 2011 the atmosphere of the workshop was pragmatic and focused on the ability to demonstrate impact credibly in an ICS. This would preoccupy UNI and other UK universities for the next two years. Many participating academics found it difficult to embrace non-academic impact in terms of proving what, outside the academy, had changed as a result of their research. As the process evolved, a distinction was made between interim impacts, which might include influencing legal or policy change, or influencing significant decision makers, and ultimate impact in the form of the beneficial outcomes that interest policy makers. It was agreed, reflecting the experiences of RCUK, that the latter was at best elusive if not impossible, requiring demonstrable links from a specific piece of research to a beneficial outcome to society, economic or otherwise. So, the concept of 'interim' impact was invented as a pragmatic and achievable conception of the ICS process. Yet even with this limitation, the evidencing of impact presented serious challenges since it required the collection of traces of impact of an entirely new kind for most academics. The ICS process also invited a kind of immodesty and self-promotion which is not stylistically suited to science.

From the outset it was made clear that academic citations do not count for impact studies except as indicators of the quality of the underlying research (which had to reach a minimum quality threshold of "two star" as noted above). Accordingly, accounting for impact would require academics to collect evidential traces at more remote points on a diffusion and 
knowledge transfer pathway than they might ordinarily be used to doing i.e beyond academia. This might include metrics and indicators but the range of evidence forms was potentially broad. What was clear from the UNI 2011 workshop and was reinforced by subsequent official guidance (Funding Councils, 2012, p.71) was that vague statements of presumed impact further along the diffusion or knowledge transfer pathway would not be credible. Narrative claims of impact, even if only of an interim nature, would need to be evidenced and 'independently verifiable' (para. 85). Initially, academic authors encountered great difficulty in being able to substantiate claims of impact - many realising that this was a non-trivial research task in its own right. At UNI, in the intense period of editing and refining the ICSs in late 2012 and 2013, this issue of evidence quality was foremost in the minds of management. Yet it was not just a question of collecting evidence of the appropriate quality 'out there'; it was also as much a process of productively 'making impact auditable' (Power, 1996: 2008) as the emergence of "solicited testimony" as an evidence form suggests.

User 'testimony' became a key form of evidence of impact. One academic cited a letter of support from the UK Prime Minister as an example. However, there was recognition that evidence forms like this letter or a citation in a public document may not exist but would have to be actively created and solicited. In short, a significant source of evidence and verifiability of research impact in the case of UNI was not entirely independent of the accounting process, waiting to be 'discovered'. Rather, testimony was actively sought, solicited and constructed. Indeed, compared to other examples of evidence given by the UK Funding Councils, solicited testimony was a low cost, achievable evidence gathering strategy which gathered momentum at UNI. 
The final 12 months before the required submission of the ICS documents was an intense process of reviewing and editing, both for compliance with the template, for clarity and style, and for evidence quality. The REF strategy oversight body for UNI met monthly in 2013 to review progress in ICS production and well as general progress towards the REF2014 submission. The committee often expressed concerns about the heavy reliance on solicited testimony. Over time some ICSs were rejected, while others were acknowledged to require much more work. As the submission due date approached, authors of ICSs lost control of their texts. The ICSs became 'owned' by a central editing process which both seconded and recruited staff, many with press and communications skillsets. Towards the end of this period and in the last month before submission in November 2013, the ICSs were no longer the property of their authors but belonged to UNI as organizational units of accounting. In the end UNI submitted over 70 impact case studies for evaluation as part of its REF submission.

\section{Accounting beginnings}

The case of accounting for research impact at UNI is interesting in its own right and to scholars of higher education. The productivist logic of use value, which has for many years influenced debates about the purpose of university research and has generated working distinctions between pure and applied research, has acquired a more generic foothold in higher education organizations via the UK research evaluation exercises. UK academic life has always been 'governed' to a greater or lesser degree and critiques of managerialism in higher education reach back decades. But the impact agenda represents a radically new point of inflexion in the mission of UK universities. 
Yet this case is also generically interesting in revealing the dynamics of how new accounting systems come about and achieve a threshold of institutionalisation. A discussion of these dynamics allows us to revisit a number of ideas from accounting scholarship in the last four decades. Inductively, the case suggests how the emergence of new forms of accounting can be conceptualised in terms of two pairs of overlapping phases, namely field-level and organization-level changes respectively. At the level of field actors - such as the UK Treasury and the UK Finding Councils - processes of policy object formation and elaboration and regulation take place. Field level changes may involve processes of event attention and collective sensemaking around critical events and initiatives (Nigam and Ocasio, 2010). In the case of research impact in the UK, it was a key report which was catalytic by virtue of reflecting and concentrating a longer term build-up of pressure for field level change. At the level of organizational actors in the field, new accountability demands in terms of a new policy object may be resisted and have a conflictual path but, if they survive, they will eventuate in a range of activities oriented towards the realisation of that object at the local organizational level. In essence this elaborative process represents practice norm creation 'from below' involving key elements, such as advocates and exemplars ('champions') who are the carriers and mediators (Latour, 2005) of external pressures and expectations. The final phase involves the accretion of these activities and their related artefactual component into a routinized and standardized system for the production of accounts, or an infrastructure for governance, data collection, analysis and monitoring. It is at this point of infrastructure creation that the accounting form acquires and consolidates its stability as a practice rather than just activity. It should be emphasised at the outset that the four schematic phases of object-orientation, though ordered in terms of a sequential logic, may influence each other dynamically and recursively over time (Halliday and Carruthers, 2007). For example, powerful organizations may originate their own preferred practices and seek to have them 
recognized and adopted at the field level (Meyer and Rowan, 1977), in which case the sequence of phases may reverse, regulatory processes may be 'captured'. Yet despite the simplicity of the framework depicted in figure 1, it provides a basis for thinking about 'more or less determinate relationships, and about pathways of influence' (Weick, 1995:389). It is a template which enables comparisons between the emergence of different accounting systems in terms of e.g., drivers of object formation, the speed of emergence and relative stability.

\section{PUT FIGURE 1 ABOUT HERE}

\section{Field level changes: Policy object formation and elaboration}

Accounting often begins with a combination of disappointment and the promise of improvement in terms of a conceptual or abstract 'performance object' as the solution. Accounting scholars have analysed this reciprocal nature of problem and solution at field levels (Robson, 1991; Miller and O'Leary, 1993) in terms of a process of 'problematization' (e.g. Foucault, 1984; Robson, 1991; Castel, 1994). Problematization in this sense is never merely individual critique or a single event, but involves the clustering of related discourses, often across and shared by different fields or arenas and often building up over time to create pressure for reform in terms of a performance object. Accounting scholars are familiar with many such performance objects: 'efficiency', 'cost-effectiveness', 'sustainability', 'value for money', 'fair value'. All these concepts derive their mobilising force from their expression of operationally-transcendent values within diagnostic policy discourses. There is a reciprocal relationship between the critique of what went before - e.g. 'waste', 'environmental degradation' and 'poor performance' - and the projection of the solution (Rose and Miller, 1992; Miller and O'Leary, 1993). 
As Burchell et al (1985) show in the case of value added, disappointment with the state of accounting in conjunction with pressure for industrial democracy and policy concerns for productivity created a focus on 'value added' as a new accountability object and value at the policy level (CCAB, 1975). In turn there followed a period of intense, though short lived, experimentation at the organization level with value added accounting statements. Burchell et al. (1985) demonstrate that accounting beginnings can be traced to multiple sources and arenas which contingently become temporarily aligned and mutually reinforcing. So problematization should not be simply equated with single critical events, although they can play an important role. As Miller and Napier (1993) suggest, new forms of accounting are likely to have multiple conditions of possibility which only contingently align.

This is not to ignore the significance of specific biographies. Hoskin and Macve (1986) document the rise of accounting as the result of the analogical adaptation and transfer of disciplinary knowledge by specific individuals between the fields of military examination and grading and functional needs for control of the railways, mediated by key individual actors. ${ }^{18}$ From this point of view the biography of key actors like Peter Warry himself - straddling academia, government and industry - is also important for the mediation of impact thinking from the general environment into higher education organizations. And yet while the UK Warry report was a significant catalyst for change, its action-generating power was itself dependent on the alignment between the wider institutional legitimacy of the idea of impact in other areas - such as development and environment noted above, specific concerns by the UK treasury, and the managerialized nature of UK universities' approach to research management following several REF exercises.

\footnotetext{
${ }^{18}$ This resembles the 'network of networks' model of innovation proposed by sociologists Padgett and Powell (2012) in which individual human agents and their biographies are the transformative links across different fields, expanding and innovating practices by analogical extension.
} 
In the case of impact accounting, higher education, like many other areas of public service provision, has experienced waves of problematization in the form of successive efforts to define and elaborate new performance concepts. And there is no new dream of performance improvement without a corresponding investment in accounting. Indeed, the demands to demonstrate the impact of research reflect general conditions of cultural rationalization which tend to drive the expansion of new forms of accounting (Meyer, 1986). Yet these accounting representations are never as secure as their projected rationality suggests and the promise of transparency often gives way to yet new forms of policy disappointment and a further dynamic of change.

Finally, two further key developments shape the elaboration of impact at the field level by regulatory actors. The first is the failure of the metrological dream envisaged by earlier policy documents which necessitated case study based forms of evaluation. We will consider this question of metrology further below. The second was the creation of a semi-standardised template (Appendix 1) for the impact studies, inductively based on several pilot studies commissioned by the regulators. The very idea of the 'pilot' study is itself a form of experimental practice production which uses discipline-specific evaluation practices, such as those found in social work, to generate a generic accounting template. It is templates like this which provide the point around which practice innovation takes place at the organizational level.

\section{Organization level changes: activity orchestration}

The case of impact accounting reveals many different kinds of effortful mediation by different actors and artefacts, but the ICS template plays a key role as a 'mediating instrument' much like the technology roadmap discussed by Miller and O'Leary (2007). It contingently links together and translates programmatic and conceptual demands into feasible 
workstreams in organizations. This linking power of the template resides in its underlying 'theorization' i.e. 'the self-conscious development and specification of abstract categories and the formation of patterned relationships such as chains of cause and effect" (Strang and Meyer, 1993: 492). The template provides a sense-making frame for the work of producing impact case studies with appropriate content in each of the sections.

Such a standardised template satisfies administrative demands to reduce the complexity and heterogeneity of potential content, and to make impact reporting manageable and auditable. Each field, sub-field and organization cannot be allowed to be so specific that its impact studies will be radically different from one another. The template, like all such accounting grids spatially organizes specific forms of knowledge in such a way that they can be made sufficiently similar and comparable. And, as many scholars have noted, often drawing on the work of Bruno Latour, such reductive templates and theorizations embody the form of mobility needed for accounting reach and durability (Robson, 1992; Quattrone, 2009; Qu and Cooper, 2011). The template is also an inscription device with classificatory and visual power (Quattrone, 2009). No-one can 'see' impact without the aid of such visual templates. The Warry report had already theorized and visualised the flow of the "pathway to impact", but the template for the ICS reconfigures and re-represents this this causal flow between the academic (research) and the non-academic worlds within an accounting instrument. In short, a particular form of causal knowledge is being imagined and "ignited" as a "possibility of beginning to practice" (Quattrone, 2009: 113) via the ICS template.

The generation of content for the ICSs emerged at UNI and other universities from an increasingly controlled dialogue between the dispersed activity of academics working with the template and a system of central oversight. Effortful mediation characterised the workstreams and flow of activity between the production of a specific ICS and the general 
idea of impact embodied in the template as a generic standard. In this process, specific norms about e.g. forms of language and precision in expression, and sufficiency of evidence came to be formed. Bottom-up local forms of theorization were generated by specific academics who became de facto internal consultants and were anointed as local exemplars of the logic of impact (cf Nigam and Ocasio, 2010). These emergent leaders of the ICS process sought to get academics to focus on the question: 'what has changed as a result of my research?' and came to form a small emergent policy community of "inscriptors" (Qu and Cooper, 2011:345) engaged in editing and rewriting the ICSs.

Although the template in Appendix 1 seems straightforward on its surface, many academics found it extraordinarily hard to internalize and to answer the question posed above by the exemplars. The impact of research had to be transformed from vague assertion into something based on traces of impact with an enduring artefactual reality (emails; letters; reports; laws; rules) and then gathered into a narrative form within the grid of the template. Yet despite considerable work to capture impact in the form of such traces, their heterogeneity and intractability was persistent leaving many academic ICS authors uncertain about whether they had 'enough' convincing evidence. The central management committee also became increasingly nervous about the credibility of solicited testimony as a dominant form of evidence in processing this heterogeneity. In some cases, as Qu and Coooper (2011) note in their study of a consulting project to build a balanced scorecard (BSC), heterogeneity is such that it can lead to failure and a number of submitted ICSs failed to 'cross the line' and were rejected. Yet the rules for being good enough emerged only slowly from a continuous process of comparison across nearly 90 draft ICSs. Each draft was a test and learning reference point for all the others. 
Accounting scholarship teaches us that the development of ICSs at UNI and elsewhere should be understood as constructing and projecting the very object - namely impact - for which the ICS is supposed to account for and somehow reflect (e.g. Hines, 1988). Indeed, the production process was more akin to invention and 'fabrication' (Preston et al. 1992) in the face of uncertainty rather than the diffusion and 'implementation' of a merely technical requirement. Despite the production of extensive guidance by bodies like HEFCE, and the intense focus of strategic committees like the one at UNI, the ambiguity of impact as a performance object pervaded the production and editing of the impact case studies, just as it has done for many other accounting initiatives.

In sum, the process at UNI suggests that the emergence of both impact accounting and its infrastructure (see below) was more a 'garbage can' form of mediation (Cooper et al, 1981; March, 1987) in which the ambiguous goal and object of impact was discovered and materialized in the very trial and error process of writing successive ICS drafts. The image is one of both regulated and regulating organizations 'making up' practice in a series of mediated iterations between a standardised template for the production of impact reports and their content. ${ }^{19}$ However, creating and stabilising the facticity of impact as a performance object at UNI required not just the development of ICSs as narrative accounting statements but also their progressive embedding in an entire apparatus or infrastructure which we now consider.

\section{Organization level changes: infrastructure and practice stabilization}

The analysis of the case of the ICS so far contains elements and concepts that are readily familiar to accounting and organization scholars - ideas of theorization, problematization,

\footnotetext{
${ }^{19}$ A consulting firm assisted with the pilot studies. In addition, see the draft advice given by the LSE Public Policy Group (2012).
} 
translation, mediation, and inscription - interested in how practices form and change. And yet, the process at UNI prior to the REF2014 submission had much less coherence than is commonly associated with a practice; it was more a set of activities informed by institutional frameworks but lacking the stability and durability that might be associated with a practice (Lounsbury and Crumley, 2011). For this stability to occur, the abstract managerial logic of use value embodied in the idea of impact had to become materialized via the accretion of roles, rules, routines and governance structures. In short, for stability there needed to be what can be provisionally labelled as an 'impact infrastructure' which can reproduce its own conventions in a more or less invisible way (Star, 2010). It is the construction of such an impact infrastructure, rather than the specific form of the ICS, which marks a decisive and radical shift in the governance of UK universities.

The idea of infrastructure may be contested but there are many hints at the significance of what might be called infrastructure-like properties within accounting scholarship (Kurunmaki and Miller, 2013). For example, Hopwood (1987) argues that we should not see forms of accounting as ‘organizationally isolated practices', outside of other processes (p.213). They are part of the active creation of regimes of control and monitoring which have to be intertwined with other parts of a management regime. In this sense the organisational production of ICSs to account for impact involves a (largely intended) organisational transformation, namely the creation of a regime. At UNI and other universities confronted by demands for impact accounting: 'what had not been controlled, but what was now seen as in need of control, was unreflected in the organisations' battery of information systems' (Hopwood, 1987: 223). Impact therefore had to become enmeshed in wider organizational processes, including routine information systems (cf also Preston et al., 1992). 
At UNI, the engagement with the ICS production process was quite late - it only really bgean in earnest in 2011 just two years before the submission date. It was initially ad hoc, relying essentially on the voluntary production of impact statements. It began with the impactful researcher being the author of his or her own impact case study. In many cases, their sole authorship was diluted as the editing process took more control of the production of the ICS as a critically important accounting statement, culminating in the use of journalists to produce "public-friendly" versions of the ICSs for eventual use on the website. This shift was symptomatic of many things, not least the crystallization of the organizational ownership and attribution of impact. Towards the end of 2013 the ICS production process had been transformed from a dispersed, local and idiosyncratic set of activities into something far more centralised. At UNI a nascent apparatus or infrastructure could be characterized by: expanded roles and resources for the press and communication office; entirely new roles in the form of an 'impact officer'; new investments in (big in potential) data collection and tracking with a focus on, and support for, knowledge exchange processes. In addition, once the ICSs had been submitted to HEFCE in November 2013, the strategy committee at UNI turned its attention to the future, the lessons learned and the problem of how to normalise and further embed the ICS production process.

In short, ICS production at UNI was not an isolated accounting statement experiment like value added accounting in the 1970s, but was deeply implicated in changing the organization. As in the case of Wedgwood, so in the case of UNI: 'In often unanticipated ways, the organisation was changed in the name of knowledge of it........what had previously been informal had now to become formal' (Hopwood, 1987: 221). Impact is now one of the factors that might determine merit pay at UNI, something which could not be imagined 
without the apparatus to document impact and transform it from a vague mission into an organizational performance fact.

The effect of infrastructure development and centralisation is to create a new normativity or performance capability at the centre of the organization. In this sense, organizationally specific infrastructure as the routine linking of information, tasks and people also has an institutional character. The ICSs must be understood not only in its technical accounting form but also as the strategic product of a broader governance ambition, or programme, to enable the activities of academics to be observed indirectly via the lenses of impact, knowledge exchange and engagement. Again, we turn to Hopwood (1987:218) who states that: 'Initiated to reveal what had been presumed to be there already, once established it provided a basis for significantly changing, if not eventually transforming the functioning of the enterprise'. He was talking about cost accounting but the point might apply equally to impact accounting.

The significance of infrastructure within the developmental scheme is also evident when it is absent. Value added accounting did not achieve the kind of organizational transformation that Hopwood describes in part because a corresponding infrastructure could not be constructed that would stabalise it. It was an experimental adjustment to existing accounting statements which became easily disregarded. Efforts to create corporate social responsibility accounting face similar challenges; accounting remains a fragile collection of inscriptions until it can generate infrastructure and this in turn is dependent on the durability of field-level institutionalization of the policy object. In contrast to Value Added and CSR, the ICS is a form of accounting 'in motion' and 'in the process of becoming' (p.323) not simply in terms of the semi-standardised template, which may well change over time, but significantly in 
terms of generating and cementing impact as a new kind of routinized fact about the organization. With the development of infrastructure, impact is transformed from an abstract 'matter of concern' to a matter of (organizational) fact (Latour, 2005).

Against the tendency to see all accounting statements as a mirror of reality, the emergence of the ICS reveals a highly effortful and 'constructive organisational endeavour.' We can say that impact has this organizing power because it: 'had operated not only as an influential abstract category entering into the language of strategy but also as a seemingly precise outcome of a specific set of accounting procedures'. This is Hopwood's (1987: 220) own version of Star's boundary object and both recognise how, over time, this movement between the abstract and the specific 'scales up' and generates the stable standards and processes that we might call infrastructure. The ICS at UNI and elsewhere is a highly specific, perhaps exotic, form of accounting. But as accounting scholars know, it is neither an 'unproblematic reflection of a more abstract intent nor a sudden discovery or transformation' (Hopwood, 1987: 227). It is rather an effortful, collective outcome of an increasingly centralised and elaborated apparatus which becomes intertwined with a range of other organisation phenomena shaping 'organisational perception, governance and strategic mobilisation.'

At UNI engagement in, and influence over, the problems of society has always been an organisational presumption, a century long mission, underwritten by many famous exemplars, and periodically celebrated. But if the position of UNI in relation to society and economy was historically supported by diverse organizational narratives about its purpose, this position could not actually become a source of organizational or performance facts until the onset of the impact accounting agenda in 2011 and the ongoing construction of an infrastructure for data collection and monitoring of impactfulness. The creation of new 
dimensions of performance and their associated facts is always radical and always requires new forms of accounting and governance.

To conclude: the REF is an evaluation exercise which formally runs every six years, yet in 2015 the strategic committee at UNI is focused on the 2020 accounting date with a view to being better prepared for the requirement to demonstrate impact. Monitoring of activities and engagements, together with potential ICSs for 2020 was underway before the results of REF2014 were known. At UNI there is still a tension its historically distinctive tradition of engagement, as a kind of 'bet' on impact and influence, and the new policy mood to demonstrate this and make impact auditable. Yet the traditional aspects of its academic practice and policy influence have become progressively formalised and controlled within a new performance regime and its processes. By December 2014 accounting for impact at UNI had well and truly begun.

\section{Agenda setting: infrastructure pressures and dynamics}

It has been argued that practice stabilisation, the fourth phase in the developmental scheme of figure 1, involves the accretion of infrastructural elements - inter alia normalized data collection processes, dedicated roles and tasks, oversight structures, and audit trails - which in turn reflect wider field-level institutionalization. This is as true for universities as it is for field-level actors such as regulators. At the time of writing it is impossible to predict how the impact agenda will unfold in the UK yet the emergence of this impact infrastructure is likely to be consequential, and existing accounting scholarship provides some clues about its possible dynamics. Three interrelated pressures for change are considered below and three 
generic propositions about the effects of infrastructure accretion are proposed as an agenda for further empirical exploration.

\section{Calculation}

The UK case study approach to impact is not itself a metrics-based one; the cases are not themselves calculative. As noted, they are standardised in a rather limited way which does not, by itself, permit the aggregation and organizational calibration of impact. This is remarkable given the generally accepted view that a 'quantifying spirit' drives accounting, and the idea that numbers, not words, are more capable of stability and resisting corruption (Robson, 1992). As narrative forms of accounting, the case studies in themselves are idiosyncratic and are not so easily mobile and combinable as metrics may be (Robson, 1992) but they are not entirely immobile. Indeed, scholars may wish to pay more attention to such variations in the mobility of accounting forms. ${ }^{20}$ However, these ICSs have been graded by evaluation committees (on the scale of "one star" to "four star") and, by virtue of that operation, have become in principle commensurable and aggregatable as a grade point average for an organization or academic sub-field. From this grading operation, the scores have been used by universities themselves and by external actors to create impact league

\footnotetext{
${ }^{20}$ It may be that new accounting forms must emerge qualitatively at first and establish themselves conceptually and operationally before they can develop more quantitative dimensions. I owe this point to Wim van der Stede, and the history of the balance scorecard is one example.
} 
tables of many different kinds. ${ }^{21}$ So the grading of narrative ICSs makes them combinable, commensurable and rankable. ${ }^{22}$

It is not impossible that the ICS regime may come to be regarded as producing too much complexity, and as increasing the costs of monitoring by central policy agencies. And there might well be contested narratives, even scandals, about the reliability of evidence of impact. $^{23}$ In terms of Burchell et al's (1980:14) suggestive framework, the ICS has the multiple roles as an ammunition machine, to defend and promote the organization in its institutional and competitive environment by making visible its positive contribution to society and economy; as a 'rationalization machine', which reduces heterogeneity and causal uncertainty into a narrative of attributable impact; and as an 'answer machine' for policy makers, to reveal the facts of impact including benefit to the UK economy. Yet this role multivalence, and the perceived frustration of dreams of precision and measurability, may generate policy disappointment leading to further pressures for accounting change. So despite the progressive embedding of an impact and knowledge exchange infrastructure, the ICS as a specific form of 'accounting in motion' (Hopwood, 1987) has only acquired provisional stability as a unit of account.

\footnotetext{
${ }^{21}$ Unlike rankings of research quality, there are no pre-existing hierarchies of prestige for impact in UK universities. The impact agenda is therefore a completely new reputational and economic stake within professional academic hierarchies and across universities. Jurisdictions and status within a system of academic disciplines (cf Abbott, 1988) are being challenged by what one might call the 'revenge of applied research'.

${ }^{22}$ For example, in the case of the Business and Management Studies sub-field see: http://results.ref.ac.uk/ByUoa/19/impact
}

\footnotetext{
${ }^{23}$ Anecdotal evidence suggests that evaluation teams in 2014 had to rely on evidence as stated and lacked the resources to conduct an audit of sources. So auditability as a design value for performance reports does not necessitate that they are actually audited.
} 
Proposition 1. The specific form and content of new accounting statements is likely to be more fragile than the infrastructures to which they give rise.

\section{Subjectivisation and reactivity}

The routinization of information flows as a feature of impact infrastructure provides for the 'reconstituting of organisational agents' (Hopwood, 1987: 229). In part, this means that subjectivisation, in the sense of the production of subjects who orient themselves towards an object and make it material (Roberts 1991; Star, 2010; Miller and Power, 2013), is at the heart of the dynamic by which accounting acquires and reproduces itself and is taken for granted. For example, Miller and O'Leary (1987) have famously shown how the invention of standard costing systems, which operationalized and routinized norms of efficiency within organizations, became a basis for judging individual and unit performance. A dense web of actions, and talk about actions, oriented to efficiency was created in which actors became enmeshed (infrastructure). They defined themselves in relation to performance norms like efficiency and formed 'incentives' in relation to it. This kind of subjectivisation is not deterministic; it is rather the creation of new spaces of practice within which actors have a certain freedom and capacity to decide, act and to constitute very specific 'situated functionalities' of practice (Ahrens and Chapman, 2007). Non-compliance with, and resistance to, prevailing performance norms is possible but the cost of this becomes increasingly high. This is the distinctive constitutive force of accounting, even on cognition itself (Ezzamel et al., 2012), which eventually may be such as to 'exclude the visibility and significance of other ways of characterising the organisational terrain' (Hopwood, 1987: 229). 
Extending this line of analysis, impact case studies must document traces of impact which may be subject to further checking and verification. ${ }^{24}$ While we do not yet know the consequences of this process of creating evidentiary traces of impact, anecdotal evidence at UNI suggests that academics are being encouraged to collect and store evidential material that they would not have previously collected; evidence gathering is to be continuous and routine rather than episodic and retrospective. There can be little doubt that the expansion of impact accounting infrastructure will shift habits and practices over time and create spaces in which academics pay more attention to impact and its evidence base.

Finally, in the case of the relatively new accounting system for impact, another kind of subjectivisation is evident, namely in the manner in which impact infrastructures may embody an underlying theorization of the research user. Young's (2006) important study of 'making up users' shows how financial reporting policy constructed over time its own internal idea of use-value and user, in part to avoid the complexity and impossibility of dealing with the multiple preferences and demand-side complexity of real users, and in part to underwrite the rationality and usefulness of accounting information. In the case of impact accounting, the abstract research user is reconstituted as an impactee who must be enrolled into the infrastructure via the efforts of academics as part of their work to acquire evidence of impact, such as 'solicited testimony'. In effect, via the ICS process, the user as impactee is being transformed into an internal referent of the accounting system. ${ }^{25}$

\footnotetext{
${ }^{24}$ As noted above, evidence of impact may be auditable but not actually audited or only partially audited. Free et al. (2009) identify the gap between the operational reality of auditing and its rhetorical promise in policy domains.

${ }^{25}$ Although there is a second class of user of the ICS regime as a whole, namely government departments and regulators who need to demonstrate productive uses of funding.
} 
To summarise, subjectivisation and reactivity effects should not be over- or understated as an outcome of new accounting processes. They should not be overstated because, as the study of the ICS regime at UNI shows, the accounting requirement does not (yet) apply to all academics. Of course were the norm for ICS production to be changed to 1 in 5 members of academic staff (which is rumoured for REF2020), we should expect very significant further organizational and disciplinary effects. So the scope and reach of accounting systems is crucial. Subjectivisation, in the sense of the creation of a new kind of academic subject, should not be understated because of effects of infrastructure creation and associated new habits of evidence collection for all academics. Subjectivization is an effect of the creation of a performance apparatus which permeates the organization, generating visibilities and orientations which are hard-wired into routines and governance systems. Dent's (1991) analysis of changes in the UK rail industry is suggestive for the 'impact culture' which is emerging in UK universities. This will undoubtedly shift academic and managerial motives, but the extent awaits further empirical research

Proposition 2: The importance of accounting to processes of subjectivization increases with the accretion of infrastructure

\section{Temporality}

Accounting and time are inextricably linked (Roberts and Scapens, 1985). The REF has been a formal reporting requirement in the UK, but it occurs every six years or so which is relatively infrequent when compared to other accounting systems. It can be predicted that future ICS production will not be an ad hoc process beginning two years before the reporting date, but will be tied into a regular, most likely continuous, system of management monitoring. So the building of practice infrastructure and related accounting requirements 
changes and even accelerates organizational time with further implications for subjectivisation discussed above.

The infrastructure of accounting for impact may influence organizational temporality in other ways. For REF2014, accounting for research impact related to research produced after January $1^{\text {st }} 1993$ - an impact 'window' of nearly two decades. This window implicitly recognised the long gestation of impacts. ${ }^{26}$ Furthermore, research in prior years was conducted in an environment where there was no impact infrastructure and impact was not a prominent policy requirement. Under these circumstances, impact, as formalised in ICSs for REF2014, was an ex post outcome of research which became visible years later, rather than an ex ante target of the research process. As Espeland and Sauder (1987) and others show, outcomes quickly become targets of management. This is already evident in the impact accounting field. For example, the social science research council - ESRC - in the UK evaluates grant applications in terms 'anticipated impacts'. So impact has become a targeted feature of the research process.

As the accretion of infrastructure reinforces impact as an organizational and individual target and shortens timeframes, researchers' methods of working are likely to change. They may even be more likely to seek to demonstrate impact before completing their research, which will then be describable as impactful. ${ }^{27}$ In this way, as Hopwood anticipated, a new accounting system can radically reconstitute an entire field of activity - in this case academic

\footnotetext{
${ }^{26}$ A research group at UNI estimated that the average lead time for impact was 6-7 years based on an analysis of all ICSs submitted.

${ }^{27}$ There are several studies which suggest that performance deteriorates when performance outcomes are made into targets - a version of "Goodhart's law". For example, Sitkin and Stickel (1996) describe how the number of successful patents at a research laboratory declined as this number was made into a target as part of greater formal control of the research process.
} 
research. As time-windows for targeted impact become shorter, research is likely to become attached to, and driven by, an ex ante focus on impact.

Proposition 3. As infrastructure accretes, it creates routines which shorten organizational time horizons.

The concept of infrastructure as used in the preceding analysis requires much more attention and explication (Kurunmaki and Miller, 2013). It sits uneasily between field-level and workbased analyses of institutionalization. It speaks to the idea of an organizational level of analysis which has been compressed on one side by the field level preoccupations of various forms of instititutional theory and on the other side by a focus on work and the microsociology of practices. In some traditions infrastructure is variously indicated by concepts of 'apparatus' or 'assemblage' or 'webs of mediators' (Latour, 2005). The idea of infrastructure can also be ontologically broad - including ideas as well as material devices or narrow, being to do with the information technology architecture and its associated routines. Yet these different labels, nuances and empirical variations suggest something common - namely the importance of integrated, linked and systematic processes for the stability of production of performance representations like impact accounting. It could be worthwhile for accounting scholars to pay more attention to the dynamic relating accounting statement origination and change to the systematic, but embedded and invisible, organization of people and artefacts oriented towards a performance value. The three propositions developed above are perhaps simplistic but they suggest a fruitful accounting research agenda

\section{Conclusions}

The requirement to account explicitly for research impact was, and is, a radical change to the operational logic of UK universities. Even though sub-disciplines and specific organizations 
may have historically oriented themselves primarily to a logic of use value, the 2014 REF in the UK has transformed this into a field-wide norm. At the centre of this transformation is the emergence of the ICS. This is an entirely new accounting device which has been used to explore the question of 'how accounting begins'. It is clear, as genealogy teaches us, that there are multiple contingent beginnings of accounting systems and we should not expect 'any general theory of crisis driven accounting change' (Hopwood, 1987 p.231). Or as institutionalists might put it: 'the emergence of new practices results from spatially dispersed, heterogenous activity by actors with varying kinds and levels of resources' (Lounsbury and Crumley, 2007: 993). Yet if there is no general theory of how accounting begins, forty years of scholarship in Accounting, Organizations and Society has nevertheless provided considerable insights into important elements of the dynamics of accounting origination, not least into how the alignment of arenas creates possibilities for agency and for innovation. This paper has created a dialogue between some of this work and the specific case of impact accounting in the UK.

A generic model of origination, in the sense of emergence, was proposed as a framework for exploring some of these dynamics. The fourfold developmental schema of object formation, object elaboration, activity orchestration and infrastructure formation provides a 'light' template for future comparative studies of accounting change of the kind that Hopwood and others accomplished. Contingent variation in the way these phases play out may explain differences in the durability and nature of accounting systems. In particular, the emergence of infrastructure - whatever is exactly intended by that term - seems to be critical in the stabilisation of new accounting forms. In the case of ICS at UNI it has been possible to see the elements of such an infrastructure in formation and the paper drew on existing scholarship 
to suggest the further consequences of its expansion, suggesting three empirically explorable propositions.

In macro-sociological terms, we can expect increased rationalization of the impact accounting agenda in the UK and its greater embeddedness as a world-level value for UK universities. What is clear from the early life of impact accounting at UNI is that an accounting system intended to neutrally reveal the facts of impact is set on a path to constitute not only the operational meaning of impact but also to radically reshape the mission and routines of the higher education organization as a totality. The engine of this process is a 'a continuous dialogue between the possible and the actual' (Hopwood, 1987: 228) in which policy ideas, aspirations and hopes mobilise very specific forms of accounting in their name, as Hopwood so often put it. These ideas become materialised in accounting practices and are also a force for infrastructure development. The peculiar reach and power of accounting lies not so much in its role as an abstract agent of something called Capitalism, but in this fusion of accounting as it is with what it might be in a continuous cycle of material self-expansion. So any specific ICS must be understood as simultaneously policy idea, routinized instrument, and narrative inscription all in one. Such a view is counterpoised to most accounting pedagogy which projects functional and stable images of accounting practices and techniques. More than anything else the contribution of Accounting, Organizations and Society over 40 years has been to bracket, if not outright reject, this presumed functionalism of accounting.

As for the specific case of accounting for the impact of research in the United Kingdom, it also has enough of its own peculiarities to warn us against any general theory both of how accounting begins and also of what accounting essentially is. But there are beginnings. One occurred in a particular organization, UNI, on a particular day $-28^{\text {th }}$ November $2011-$ and 
initiated the to and fro between an abstract policy value - impact - and its manifestation in an accounting instrument. As Hopwood (1987:213) reminds us, we should not automatically assume that a specific form of accounting is ever 'adequate to the ends in the name of which it is advanced'. So it is possible, and even likely, that the current form of accounting for research impact will generate further forms of disappointment, creating new cycles of problematisation and theorization. This is what makes accounting endlessly interesting. It will always confound our accounts of it. 


\section{References}

AACSB (2008). The Impact of Research. Tampa, FL.: The Association to Advance Collegiate Schools of Business.

Abbott, A. (1988). The system of professions. Chicago: University of Chicago Press.

Ahrens, T. and Chapman, C. (2007). Management accounting as practice. Accounting, Organisations and Society. 32 (1-2):

Burchell, S. et al (1980). The roles of accounting in organizations and society. Accounting, Organizations and Society 5(1):5-27

Burchell, S., Clubb, C., \& Hopwood, A. G. (1985). Accounting in its Social Context: Towards a History of Value Added in the United Kingdom. Accounting, Organizations and Society, 10(4), 381-413.

Castel, R., "Problematisation" as a Mode of Reading History, in J. Goldstein (ed.), Foucault and the Writing of History, Oxford: Blackwell, 1994.

CCAB (1975). The Corporate Report. London: Consultative Committee of Accountancy Bodies

Colini, S. (2009). The humanities and the REF. Times Literary Supplement, November 13.

Cooper, D., Hayes, D., and Wolf, F. (1981). Accounting in organized anarchies: understanding and designing accounting systems in ambiguous situations. Accounting, Organisations and Society. 6(3):175-191.

Corbyn, Z. (2008). Councils admit defeat in hunt for algorithm to show economic value of research. Times Higher Education March 6. 
Dasgupta, P. and David, P. (1994). Towerds a new economics of science. Research Policy 23:487-521.

Dent, J. (1991). Accounting and organizational cultures: a field study of the emergence of a new organizational reality. Accounting, Organisations and Society. 16(8):

Eisenhardt, K. (1989). Building theories from case study research. Academy of Management Review 14(4):532-550.

Espeland, W. and Sauder, M. (2007). Rankings and reactivity: how public measures recreate social worlds. American Journal of Sociology 113:1-40

ESRC (2009). Taking Stock: A Summary of ESRC's Work to Evaluate the Impact of Research on Policy and Practice. Swindon: ESRC

Etzkowitz, H. (2003). Research groups as 'quasi firms': the invention of the entrepreneurial university. Research Policy 32:109-121.

Ezemenari, K., Rudqvist, A, and Subbarao, K. (1999). Impact evaluation: a note on concepts and methods. Washington DC: The World Bank

Ezzamel, H., Robson, K. and Stapleton, P. (2012). The logics of budgeting: theorization and practice variation in the educational field. Accounting, Organisations and Society. 37(5):281303.

Foucault, M. (1984). Polemics, Politics, and Problemizations: An Interview with Michel Foucault. In P. Rabinow (Ed.), The Foucault Reader: An Introduction to Foucault's Thought (pp. 381-390). London: Penguin Books. 
Free, C. , Salterio, S. and Shearer, T. (2009). The construction of auditability: MBA rankings and assurance in practice. Accounting, Organizations and Society 34:119-140

Funding Councils (2010). Research Excellence Framework: Impact pilot exercise - Example case studioes from Social Work and Social Policy. Bristol, UK: HEFCE.

Funding Councils (2011). Decisions on assessing research impact. Bristol, UK: HEFCE.

Funding Councils (2012) Panel Criteria and Working Methods. Bristol, UK: HEFCE

Garrett-Jones, S. (2000). International trends in evaluating university research outcomes:

what lessons for Australia? Research Evaluation 8(2):115-124.

Geuna, A. and Martin, B. (2003). University research evaluation and funding: an international comparison. Minerva 41: 277-304.

Habermas, J. (1987). The idea of the university: learning processes. New German Critique 41:3-32.

Halliday, T. and Carruthers, B. (2007). The recursivity of law: global norm-making and national law making in the globalization of corporate insolvency regimes. American Journal of Sociology. 112: 1135-1202.

Head, S. (2011). The grim threat to British Universities. The New York Review of Books. January $13^{\text {th }}$.

Hines, R. (1988). Financial accounting: in communicating reality, we construct reality. Accounting, Organizations and Society 13(3):251-61. 
Hopwood, A.G. (1987). The archaeology of accounting systems. Accounting, Organizations and Society 12(3):207-34.

Hoskin, K and Macve, R. (1986). Accounting and the examination: a genealogy of disciplinary power. Accounting, Organizations and Society 11(2): 105-36.

Khandker, S. Koolwal, G., and Samad, H. (2010). Handbook on impact evaluation: quantitative methods and practices. Washington DC.: The World Bank.

Kurunmaki, L. and Miller, P. (2013). Calculating failure: the making of a calculative infrastructure for forgiving and forecasting failure. Business History 55(7):1100-1118.

Latour, B. (2005). Reassembling the social. Oxford: Oxford University Press

Lawrence, T., Suddaby, R. and Leca, B. (2011). Institutional work: refocusing institutional studies of organization. Journal of Management Inquiry 20(1):52-58.

Lounsbury, M. and Crumley, E. (2007). New practice creation: an institutional perspective on innovation. Organization Studies 28(7): 993-1012

LSE Public Policy Group (2012). Maximizing the impacts of your research: a handbook for social scientists.

Mansfield, E. (1991). Academic research and industrial innovation. Research Policy 20: 112.

March, J. (1987). Ambiguity and accounting: the elusive link between information and decision making. Accounting, Organisations and Society. 12(2):153-168

Meyer, J. (1986). Social environments and organizational accounting. Accounting, Organisations and Society. 11(4-5):345-356 
Miller, P and Napier, C. (1993). Genealogies of calculation. Accounting, Organisations and Society. 18(7/8):631-47.

Miller, P. and O'Leary, T. (1987). Accounting and the construction of the governable person. 12(3):235-265.

Miller, P. and O'Leary, T. (2007). Mediating instruments and making markets: capital budgeting, science and the economy. Accounting, Organizations and Society 32:701-34.

Miller, P. and Power, M. (2013). Accounting, organizing and economizing: connecting accounting research and organization theory. The Academy of Management Annals 7(1):557-605.

Miller, P., \& O'Leary, T. (1993). Accounting Expertise and the Politics of the Product: Economic Citizenship and Modes of Corporate Governance. Accounting, Organisations and Society, 18(2/3), 187-206.

Narin, F., Hamilton, K. and Olivastro, D. (1997). The increasing linkage between US technology and public science. Research Policy 26: 317-330.

Nigam, A. and Ocasio, W. (2010). Event attention, environmental sense-making, and change in institutional logics: an inductive analysis of the effects of public attention to Clinton's Health Care Reform initiative. Organization Science 21(4):823-841.

Padgett, J. and Powell, W. (2012). The problem of emergence. In J. Padgett and W. Powell (eds). The Emergence of Organizations and Markets. Princeton NJ:, Princeton University Press. 
Pavitt, K. (1991). What makes basic research economically useful? Research Policy 20: 109-119.

Power, M. (1996). Making things auditable. Accounting, Organisations and Society. 21(2-3)

Power, M. (2008). Research evaluation in the audit society. Wissenschaft unter beobachtung $1: 15-24$.

Preston, A., Cooper, D. and Coombs, (1992). Fabricating budgets. Accounting, Organisations and Society. 17(6):561-593.

Qu, S and Cooper, D. (2011). The role of inscriptions in producing a balanced scorecard. Accounting, Organizations and Society 36: 344-362.

Quattrone, P. (2009). Books to be practiced: memory, the power of the visual and the success of accounting. Accounting, Organizations and Society 34(1): 85-118.

Roberts, J. (1991). The possibilities of accountability. Accounting, Organizations and Society. 16(4):355-68.

Roberts, J. and Scapens, R. (1985). Accounting systems and systems of accountability understanding accounting practices in their organizational contexts. Accounting, Organisations and Society. 10(4):443-456.

Robson, K (1994). Connecting science to the economic: accounting calculation and the visibility of research and development. Science in context 7(3):497-514.

Robson, K. (1991). On the Arenas of Accounting Change: The Process of Translation. Accounting, Organisations and Society, 16(5-6), 547-570. 
Robson, K. (1992). Accounting numbers as "inscription": action at a distance and the development of accounting. Accounting, Organisations and Society. 17(7):685-708.

Rose, N. (1991). Governing by numbers: figuring out democracy. Accounting, Organizations and Society 16(7):673-92.

Rose, N. and Miller, P. (1992). Political power beyond the state: problematics of government. British Journal of Sociology 43:173-205.

Sitkin, S. and Stickel, D. (1996) The road to hell: the dynamics of distrust in an era of quality. In Kramer, D. and Tyler, T. (eds.) Trust in Organizations. Thousand Oaks, CA: Sage, 196-215.

Star, S. (2010). This is not a boundary object: reflections on the origin of a concept. Science, Technology and Human Values 35(5):601-17.

Strang, D. and Meyer, J (1993). Institutional conditions for diffusion. Theory and Society 22(4):487-511.

Technopolis Ltd., (2010). REF Research impact pilot exercise: lessons learned project: feedback on pilot submissions. London, November.

Van Raan, A. (2005). Fatal attraction: conceptual and methodological problems in the ranking of universities by bibliometric methods. Scientometrics 62(1):133-143.

Warry Report (2006). Increasing the economic impact of research councils: Advice to the Director General of Science and Innovation from the Research Council Economic Impact Group. London: BIS. 
Weick, K. (1995). What theory is not, theorizing is. Administrative Science Quarterly 40(3):385-390.

Weingart, P. (2005). Impact of the bibliometrics upon the science system: inadvertent consequences. Scientometrics 62(1):117-131.

Young, J. (2006) Making up users. Accounting, Organizations and Society 31(6):579-600. 


\section{Appendix 1}

Extract from HEFCE 2012b Annex G Impact case study template and guidance

"Each case study should include sufficiently clear and detailed information to enable panels to make judgements based on the information it contains, without making inferences, gathering additional material, following up references or relying on members' prior knowledge. References to other sources of information will be used for verification purposes only, not as a means for panels to gather further information to inform judgements."

Impact case study template (REF3b)

\section{Title of case study:}

1. Summary of the impact (indicative maximum 100 words)

This section should briefly state what specific impact is being described in the case study.

2. Underpinning research (indicative maximum 500 words)

This section should outline the key research insights or findings that underpinned the impact, and provide details of what research was undertaken, when, and by whom. References to specific research outputs that embody the research described in this section, and evidence of its quality, should be provided in the next section.

3. References to the research (indicative maximum of six references)

This section should provide references to key outputs from the research described in the previous section, and evidence about the quality of the research.

4. Details of the impact (indicative maximum 750 words)

This section should provide a narrative, with supporting evidence, to explain:

- $\quad$ how the research underpinned (made a distinct and material contribution to) the impact

- $\quad$ the nature and extent of the impact.

The following should be provided:

- A clear explanation of the process or means through which the research led to, underpinned or made a contribution to the impact (for example, how it was disseminated, how it came to influence users or beneficiaries, or how it came to be exploited, taken up or applied).

- Details of the beneficiaries - who or what community, constituency or organisation has benefitted, been affected or impacted on.

- Details of the nature of the impact - how they have benefitted, been affected or impacted on.

- Evidence or indicators of the extent of the impact described, as appropriate to the case being made.

- Dates of when these impacts occurred. 


\section{Sources to corroborate the impact (indicative maximum of 10 references)}

This section should list sources external to the submitting HEl that could, if audited, provide corroboration of specific claims made in the case study. Sources provided in this section should not be a substitute for providing clear evidence of impact in section 4; the information in this section will be used for audit purposes only.

This section should list sufficient sources that could, if audited, corroborate key claims made about the impact of the unit's research. These could include, as appropriate to the case study, the following external sources of corroboration (stating which claim each source provides corroboration for):

- Reports, reviews, web links or other documented sources of information in the public domain.

- Confidential reports or documents (if listed, these must be made available by the HEI if audited).

- Individual users/beneficiaries who could be contacted by the REF team to corroborate claims*.

- Factual statements already provided to the HEI by key users/beneficiaries, that corroborate specific claims made in the case study and that could be made available to the REF team by the HEI if audited*.

* Where the sources are individuals who could be contacted or have provided factual statements to the HEI, the submitted case study should state only the organisation (and, if appropriate, the position) of the individuals concerned, and which claim(s) they can corroborate. Their personal details (name, position, contact details) must be entered separately on the REF submission system and not on REF3b. Details of a maximum of five individuals may be entered for each case study; these data will not be published as part of the submission. 


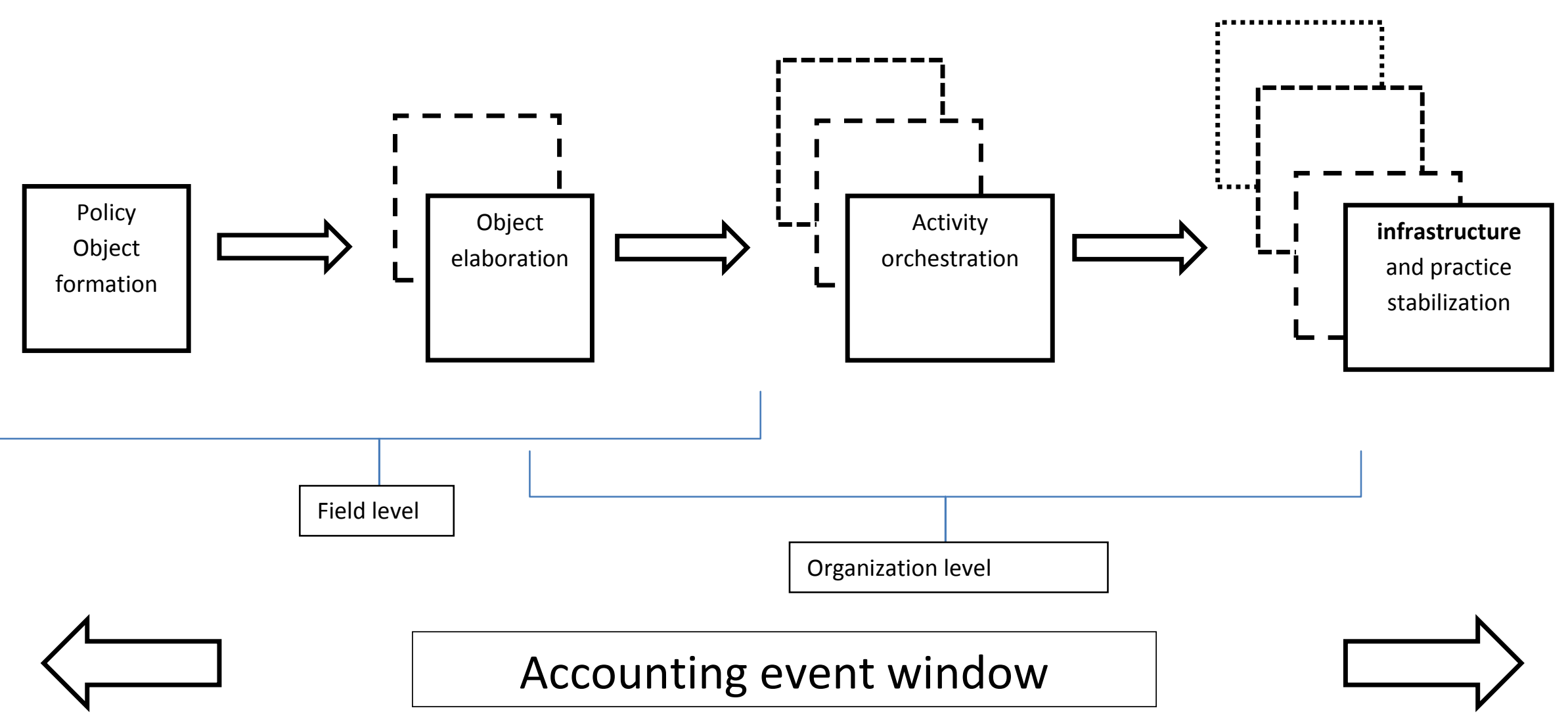

Figure 1: Phases in the emergence of new accounting forms 